\title{
Mandibular Fractures and their Radiographic Diagnosis
}

\section{Latika Bachani Chopra ${ }^{1 *}$, Ashok Lingappa ${ }^{2}$, Monika Singh $^{3}$ and Anshul $^{3}$}

${ }^{1}$ Assistant Professor, Department of Oral Medicine and Radiology, Faculty of Dental

Sciences, SGT University, Haryana, India

${ }^{2}$ Professor and Head, Department of Oral Medicine and Radiology, Bapuji Dental

College and Hospital, Karnataka, India

${ }^{3}$ Post Graduates, Department of Oral Medicine and Radiology, Faculty of Dental

Sciences, SGT University, Haryana, India

*Corresponding Author: Latika Bachani Chopra, Assistant Professor,

Department of Oral Medicine and Radiology, Faculty of Dental Sciences, SGT

University, Haryana, India
Received: June 15, 2020

Published: July 02, 2020

(C) All rights are reserved by Latika Bachani

Chopra., et al.

\section{Abstract}

When a patient who has sustained facial trauma is brought to our clinic, the question of bony involvement arises in our mind. The accurate diagnosis of fractures depends upon a thorough clinical examination followed by appropriate radiographic diagnosis. Hence, it would be wise to say that clinical and radiographic examination go hand in hand for the diagnosis of fractures.

Keywords: Mandibular Fractures; Radiographic Diagnosis; Facial Trauma

\section{Introduction}

When a patient who has sustained facial trauma is brought to our clinic, the question of bony involvement arises in our mind. Many a times we consider the trauma to be minor, but it is not uncommon to unearth radiographically, fractures that were clinically unsuspected. Conversely, a clinically suspected fracture may not be demonstrable radiographically. Hence, it would be wise to say that clinical and radiographic examination go hand in hand for the diagnosis of fractures [1].

\section{Anatomy of mandible}

The mandible is a tubular bone bent into a horse-shoe shape.

As with all tubular bones, their strength is derived from the dense cortical plates that encase variable amounts of cancellous marrow spaces. It is strongest at the midline with progressively less strength towards the condyles [2].

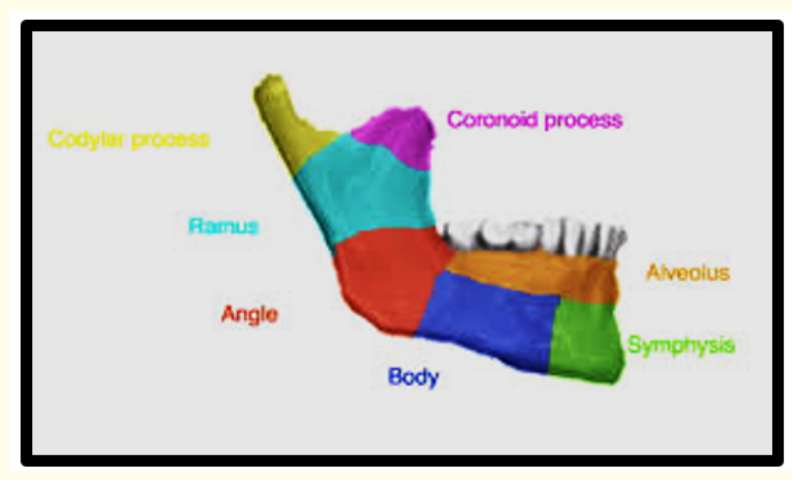

Figure 1

Muscle attachments to mandible

This mandibular bone provides attachments to various muscles at various locations which can be appreciated in this diagram. It is 


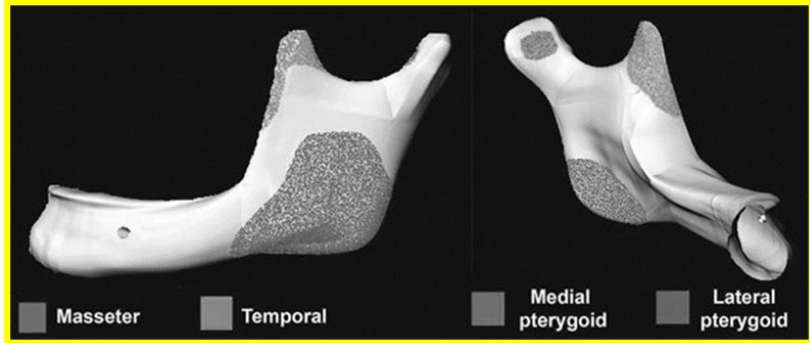

Figure 2

important for us to understand the attachment of these muscles because in mandibular fractures, the displacement of the fractured fragments depends upon the action of these muscles [3].

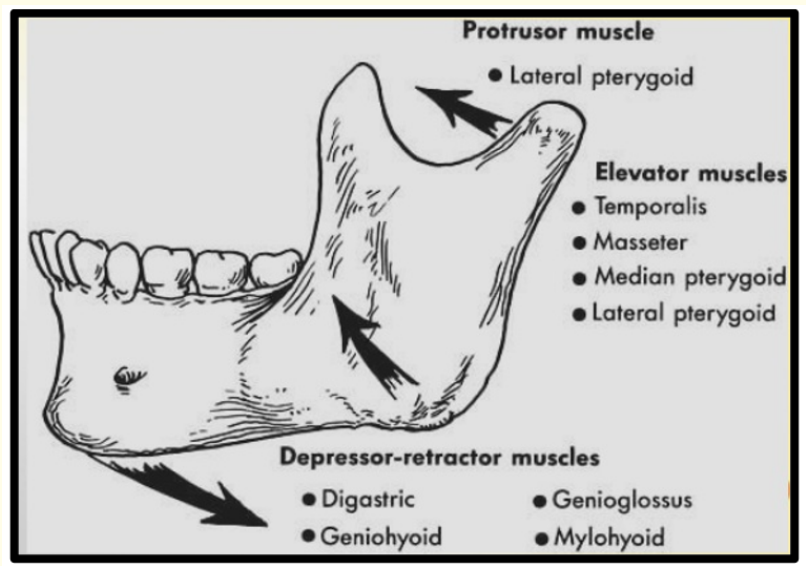

Figure 3

\section{Epidemiology}

- Mandibular fractures: 36 - 70\% of all maxillofacial fractures.

- $\quad$ Males $>$ Females aged $16-30$ years [4].

Biomechanics of mandible fractures

- Like any other bone, mandible also fractures at sites of tensile strain when subjected to a compressive loading force.

- The amount of force required to fracture the mandible is $44.6-74.4 \mathrm{Kg} / \mathrm{m}^{2}$.

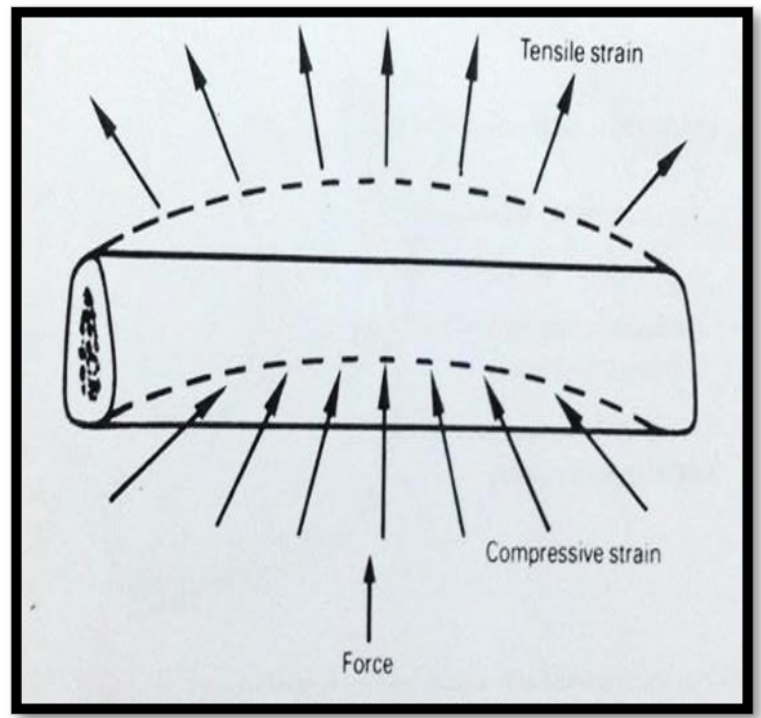

Figure 4

- However, patients' with poor medical conditions such as osteoporosis, bone neoplasm, hyperparathyroidism and on prolonged steroid therapy will have their mandible weakened by these conditions and fracture below this force.

Hunting bow concept

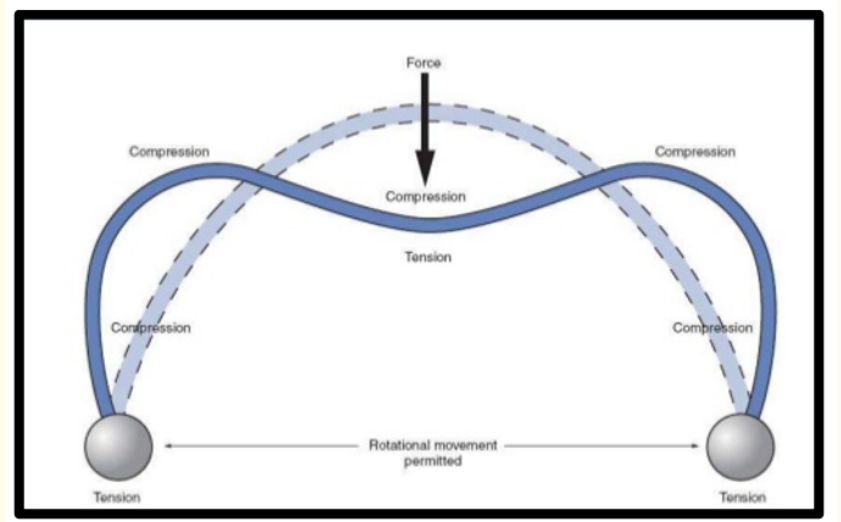

Figure 5

The mandible is similar to a hunting bow in shape, strongest in the midline (symphysis) and weakest at both ends (condyles). The 
most common area of fracture in the mandible is therefore the condylar region.

A blow to the anterior mandibular body is the most common reason for condylar fracture. The force is transmitted from the body of the mandible to the condyle. The condyle is trapped in the glenoid fossa. Commonly, a blow to the ipsilateral mandible causes a contralateral fracture in the condylar region. If the impact is in the midline of the mandible, fractures of the bilateral condylar region are very common [5].

Patterns of distribution of tensile strain on mandible

$75 \%$ of mandibular fractures begin in areas of tension.

Exception: Comminuted intra-capsular condylar fracturescompression in origin.

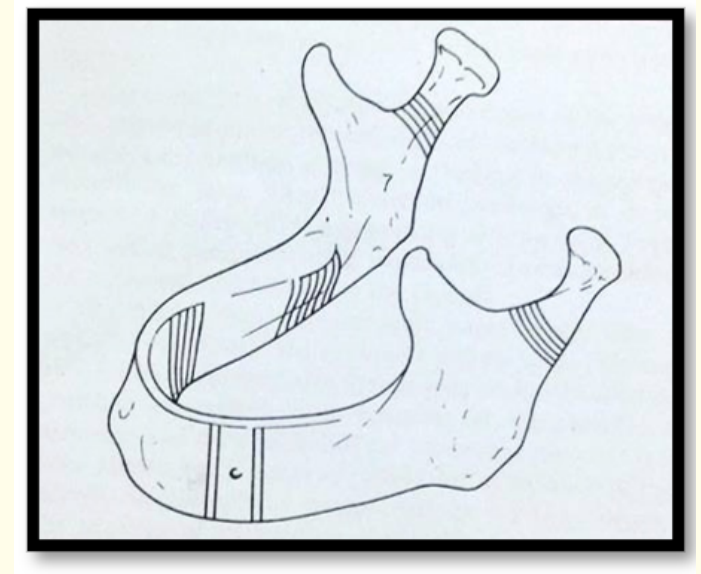

Figure 6

Forces applied over symphysis region or over mental foramen region lead to strain at the condylar neck and along the lingual plates in the opposite molar region [6].

\section{Ring bone rule}

- The stiffer a ring bone is, the more likely it is to break in more than one place. The more flexible it is, the more likely it is to break in just one place.

- The rule states that "if one fracture is present, look for another fracture" [5].
- Injuries leading to mandibular fractures are influenced by various factors such as:

- Severity and anatomical sites of impacting force,

- Whether the mouth was opened or closed at the time of injury,

- The presence or absence of teeth and

- The cross sectional area of bone.

- If the force is severe enough, both the site of application and the other distant sites may fracture as obtains in contre-coup fractures.

- However, if the force is less severe as in blows of the fist, the bones will facture at its weakest point.

- The nature of the trauma and the direction of the force that is applied often foretell the type of fracture injury.

- A patient who is hit on the side of his face: Ipsilateral body fracture and contralateral condylar fracture.

- An impact at the central symphysis: Bilateral condylar fractures with symphyseal or parasymphyseal fracture (the classic "triple fracture") [7].

Akama., et al. and Roode., et al. found out that the region of the mandible that most frequently fractures at one site is the angle of the mandible while the area that fractures at more than one site following a singular impact are the condyles [8].

\section{Location of mandibular fractures [9]}

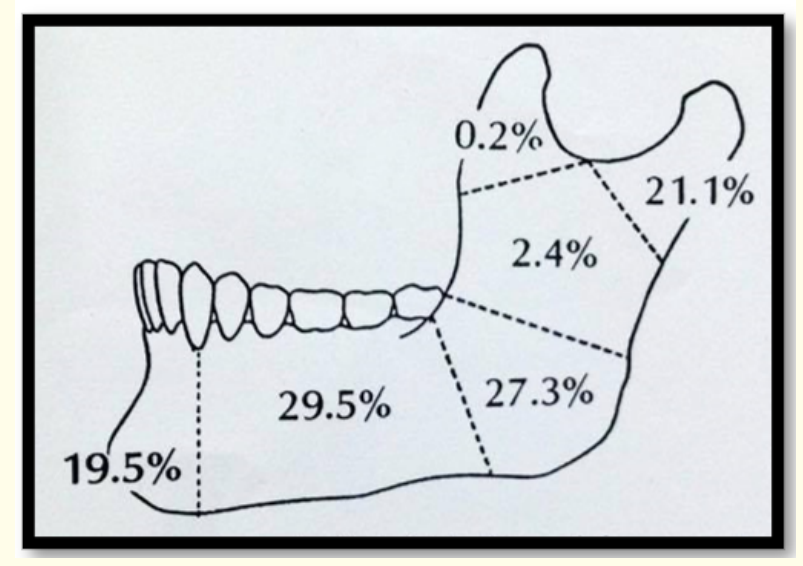

Figure 7 


\section{Classification of injury to the bone of TMJ}

\section{Dislocation}

- Anterior

- Posterior

- Lateral

- Superior

Fracture [10]

Usually an indirect one.

Localisation: Subcondylar > condylar neck > intra-capsular.

Fracture at the angle of mandible

Weakness at this point is due to:

- Change in direction between body and ascending ramus.

- Position of third molar [11].

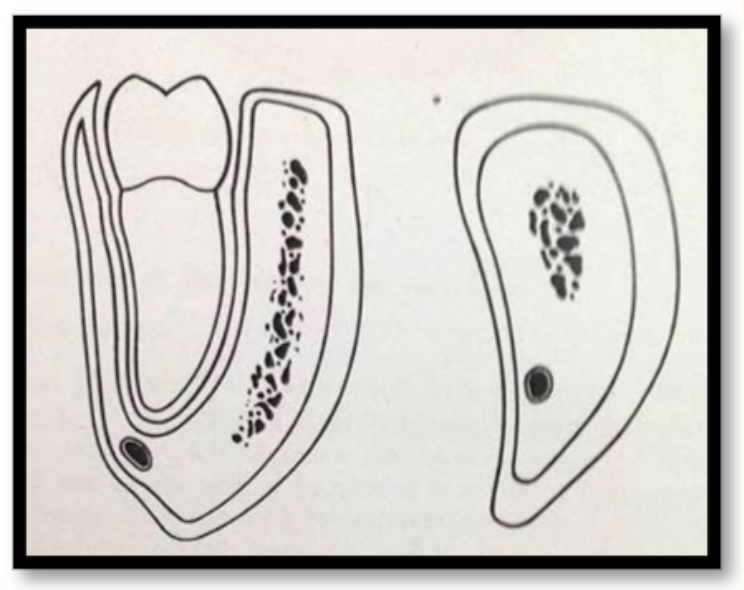

Figure 8

\section{Displacement}

- Vertically Favorable vs. unfavorable

- Horizontal Favorable vs. unfavorable.

- Action of Masseter, Temporalis, Medial pterygoid and Lateral pterygoid on the angle: pull the proximal segment upward and medially.

- Action of Geniohyoid, Genioglossus and Diagastric on the symphysis: pull the fractured fragment inferiorly and posteriorly.

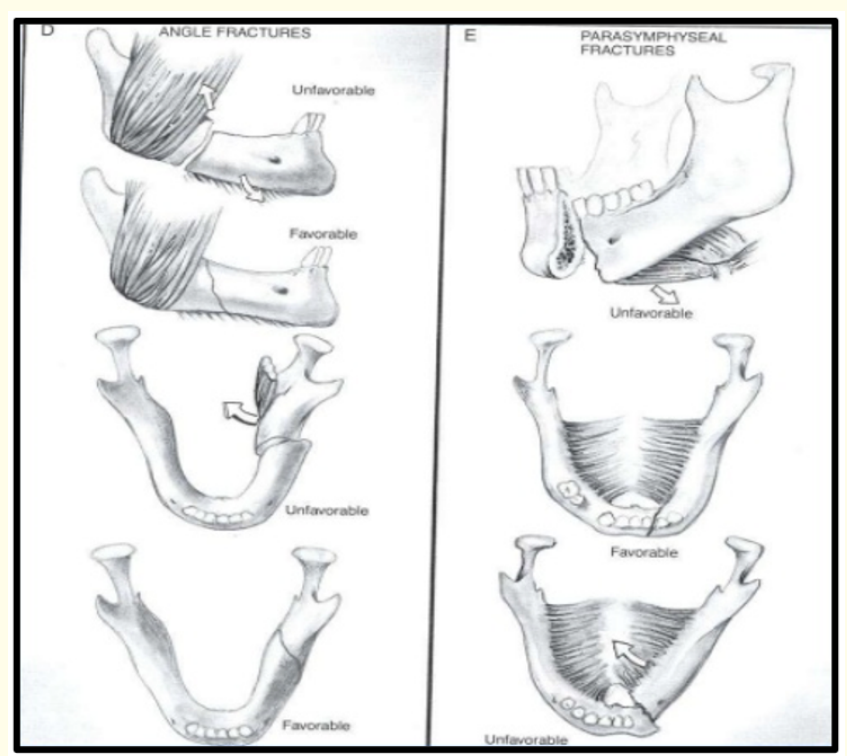

Figure 9

- When the fractures are vertically and horizontally unfavorable, the fragments tend to be displaced.

- These same muscles tend to stabilize the bony fragments in horizontally and vertically favorable fractures [2].

Fracture at the Body of mandible

Localisation: In the first molar or the canine region [11].

Symphysis fracture

- Mostly oblique.

- Fragment with attached geniohyoid displaced lingually.

- Two fractured fragments tend to rotate medially due to pull of mylohyoid [12].

Multiple fractures of mandible

- Fracture of body and opposite side angle [13].

- Bilateral subcondylar fractures.

- Flial Mandibular Fracture

- Symphysis + bilateral subcondylar fracture

- $\quad$ Flaring of angles and bodies laterally [12]. 


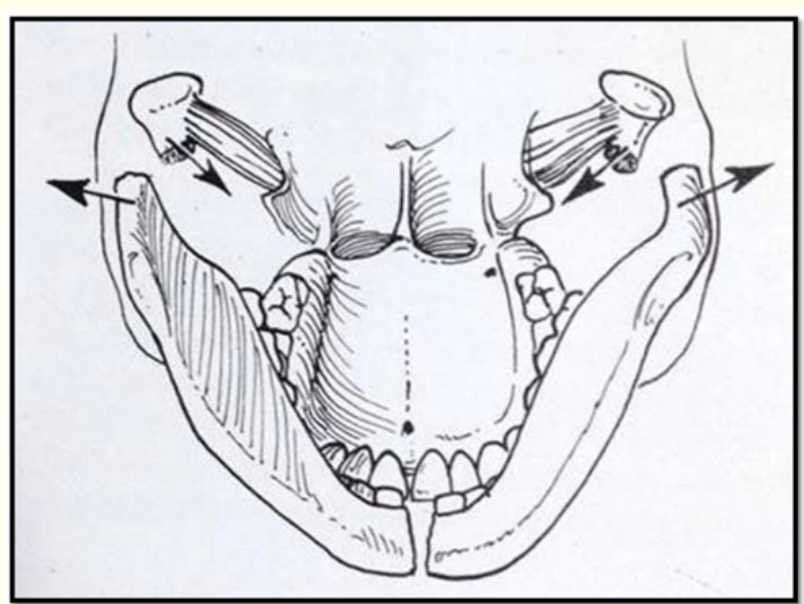

Figure 10

\section{Guardsman fracture}

- Parade ground fracture

- Caused by a fall on the midpoint of the chin.

- Fracture of the symphysis and both condyles.

- It is usually seen in epileptics, elderly patients and occasionally in soldiers [14].

\section{Radiologic assessment of mandibular fractures}

To assess:

- The presence, location and orientation of fracture planes and fragments.

- Involvement of nearby vital anatomic structures.

- Foreign objects, if any, have got embedded within the soft tissues.

- Extent of healing in the follow-up images [15].

\section{Radiographic signs of fracture}

- Presence of one or two usually sharply defined radiolucent lines within the anatomic boundaries of a structure.

- A change in the normal anatomic outline or shape of the structure.

- A loss of continuity of an outer border.

- An increase in the radiopacity of a structure [16].
Effect of position of X-ray beam on to the final image [17]

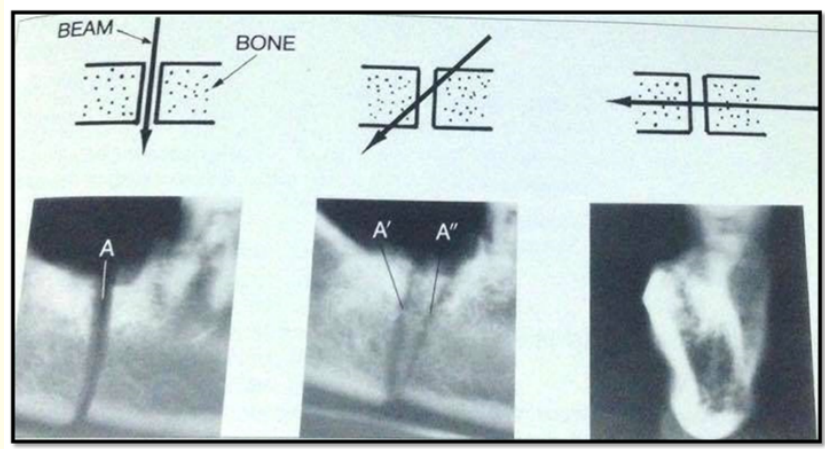

Figure 11

\begin{tabular}{|lll|}
\hline Radiographic sign & \multicolumn{1}{c}{ Type } & \multicolumn{1}{c|}{ Physical bone changes } \\
\hline Fracture line & - Single, well-defined, dark & - One bony seperation \\
& - Double, ill-defined, less dark & - One bony seperation \\
& - Double, well-defined, dark & - Two bony seperations \\
\hline Displacement & - Cortical step & \\
\hline Deformity & - Radiopaque band & - Discontinuity of bone \\
& - Decreased horizontal or vertical & - Proximal segments overlap \\
& bone dimension & \\
\hline
\end{tabular}

Figure 12

Ideally, 2 radiographic views of the fracture that are oriented $90^{\circ}$ from one another are needed to properly work up fractures.

\section{Radiographs of importance in mandibular fractures}

- OPG

- PA view mandible

- Oblique lateral view body and ramus

- Reverse towne projection

- Mandibular occlusal views

- Intraoral periapical views

\section{Imaging}

Initial screening of patients is most effective with a panoramic radiograph, since it shows the entire mandible including the condyles [16]. 
Symphyseal and parasymphyseal fracture

- Our screening radiograph i.e. OPG would fail to reveal the fractures in this region!

- Shadow of cervical spine.

Occlusal view is taken to view symphyseal fractures.

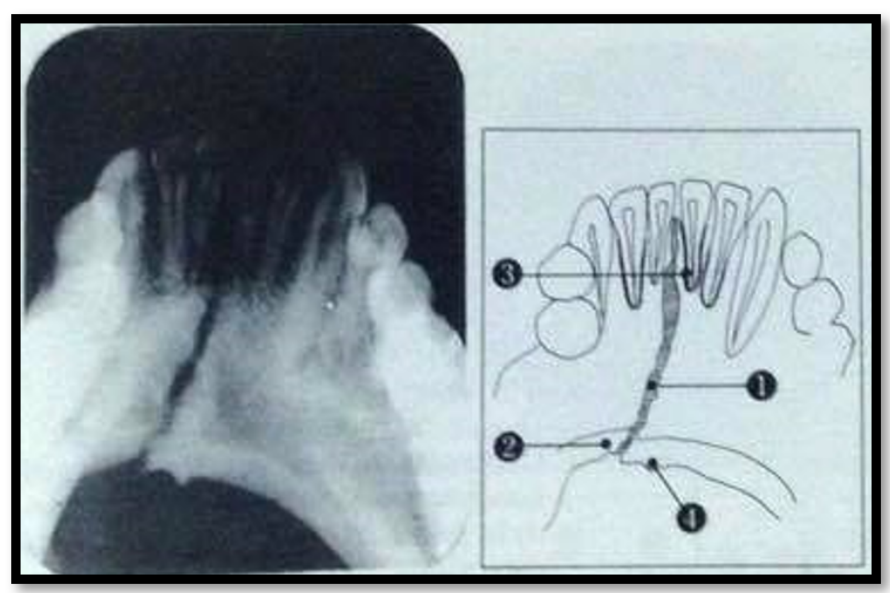

Figure 13

\section{Body fracture}

OPG [16]

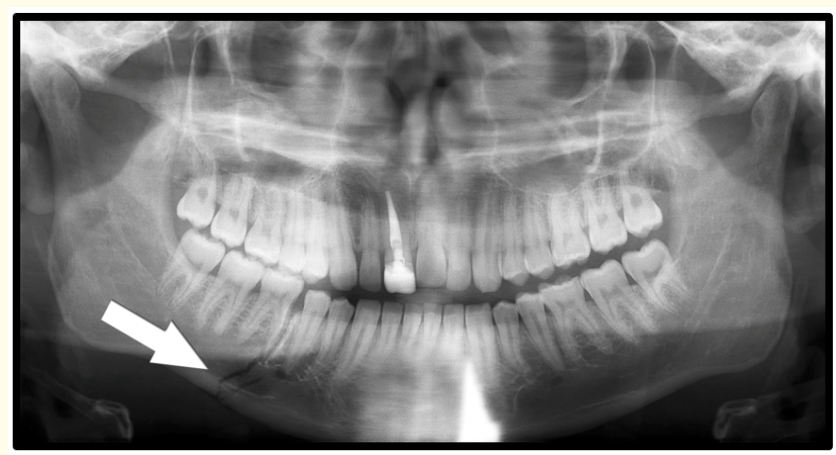

Figure 14
Lateral oblique body view

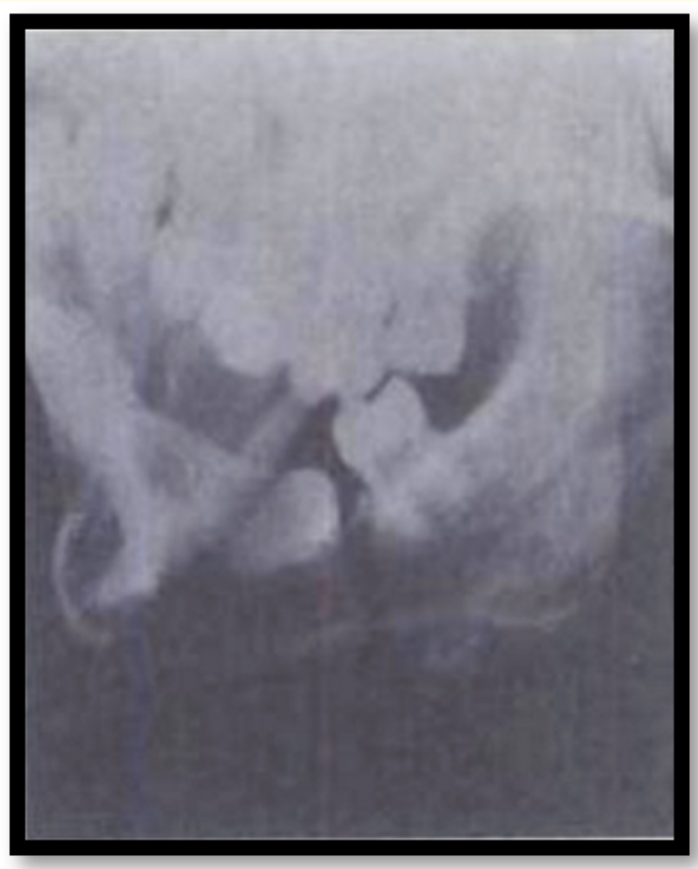

Figure 15

\section{Bucket handle fracture [15]}

In case of overriding Of Fracture Fragments; an occlusal view should be taken to see the displacement of the fragments [17].

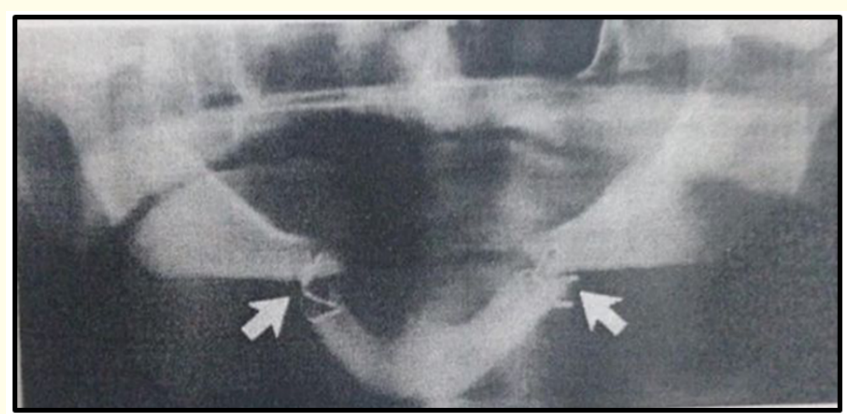

Figure 16 


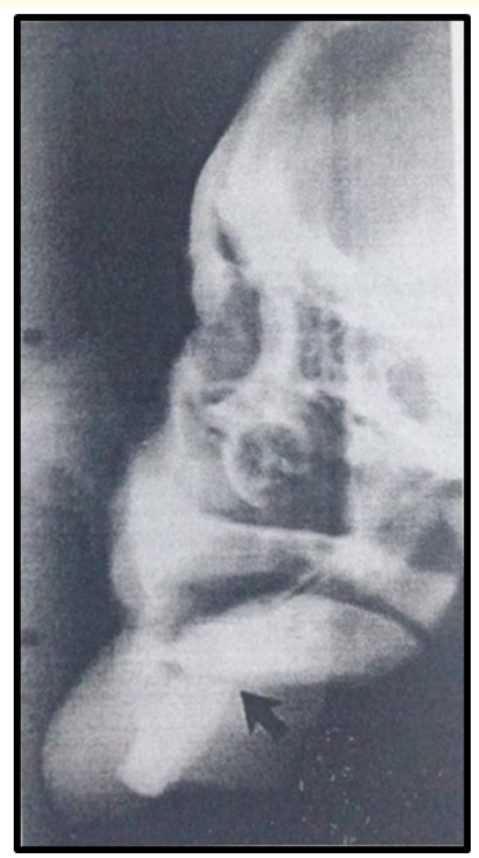

Figure 17

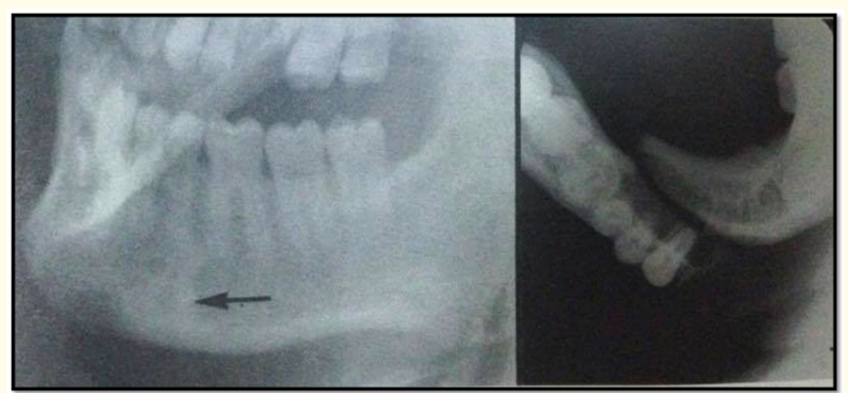

Figure 18

What if there is an oblique fracture?

- Can escape detection on an OPG!

- Advise occlusal view to show displacement of the fragments [18].

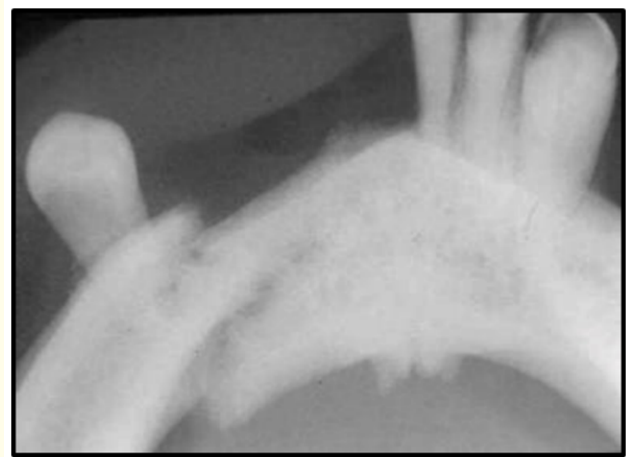

Figure 19

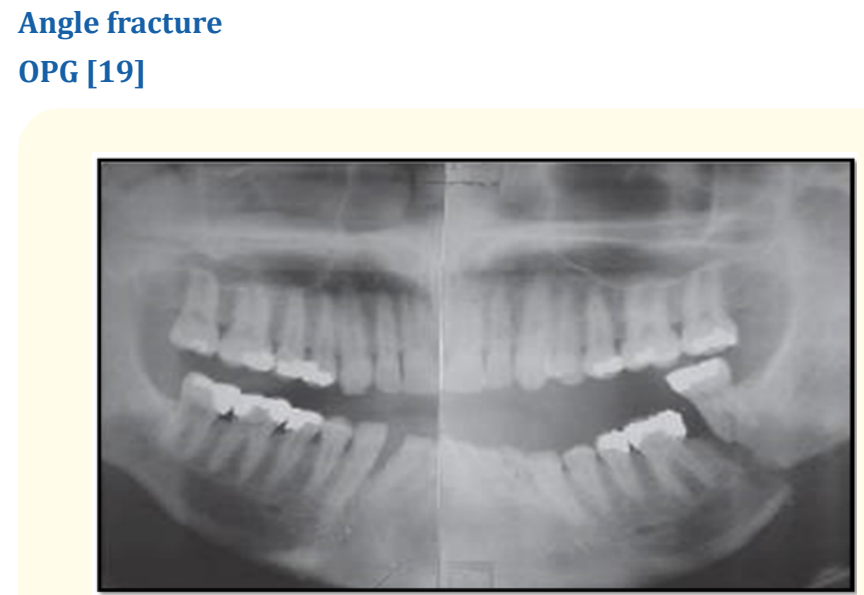

Figure 20

PA Mandible View: To assess the medio-lateral displacement of the fragments [17].

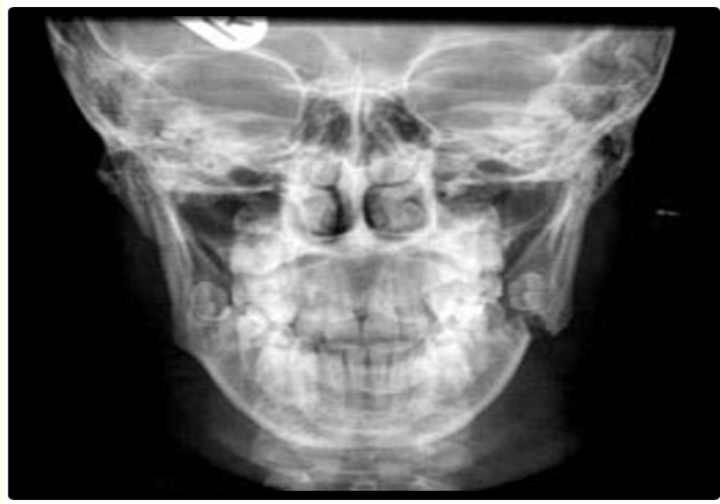

Figure 21 
Ramus fracture

OPG [20]

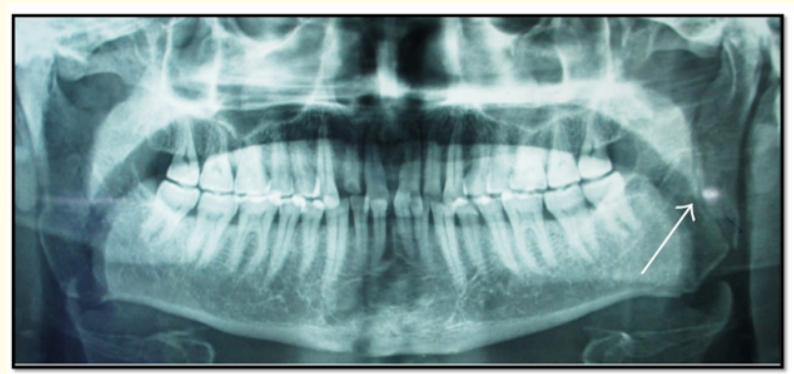

Figure 22

PA mandible view [18]

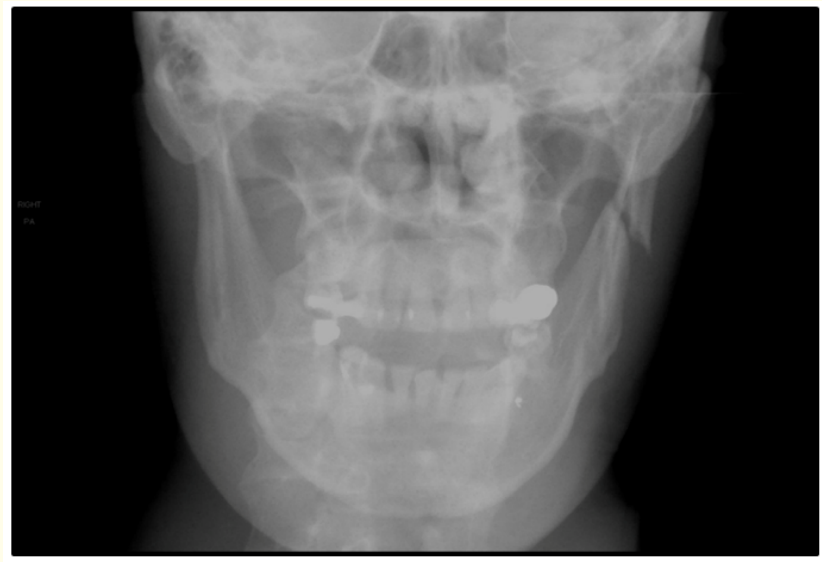

Figure 23

Condylar fracture

Initial screening: OPG

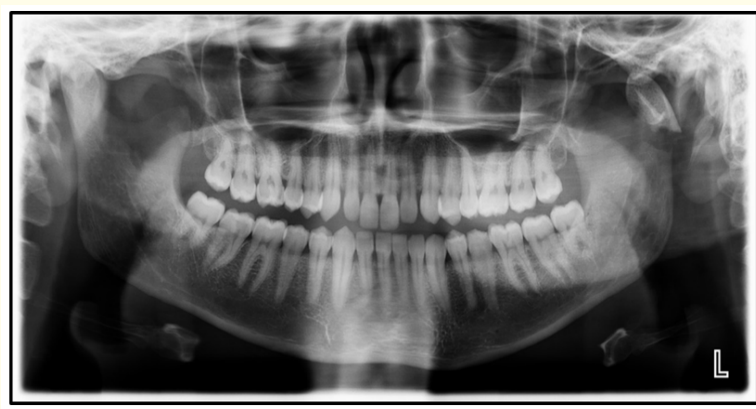

Figure 24
The panoramic radiograph is the conventional form of radiography used, giving an overall view of the fractured mandible and showing the displacement of the fractured condylar process in the anterio-posterior direction, but not in the latero-medial direction [21].

Reverse towne projection

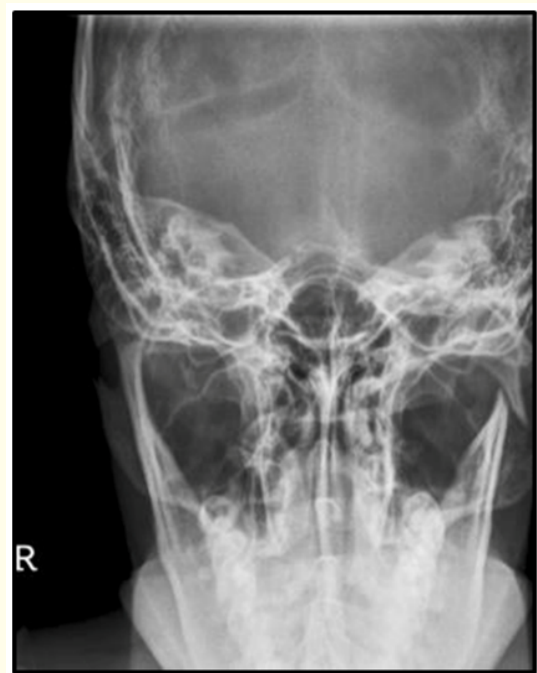

Figure 25

- Eliminates the superimposition of mastoid and zygoma over the condylar neck region which was present in PA view.

- Indicated to view high condylar or intra-capsular fractures of condyle.

- Shows the medial or lateral displacement of the condylar head [19].

Transcranial view: To view the joint space and condylar head.

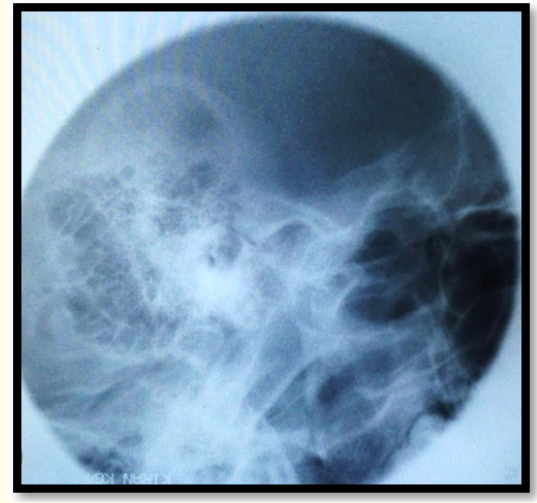

Figure 26 


\section{Transpharyngeal view}

- To evaluate fracture of condylar head and neck.

- To evaluate the antero-posterior displacement of the fractured conylar head.

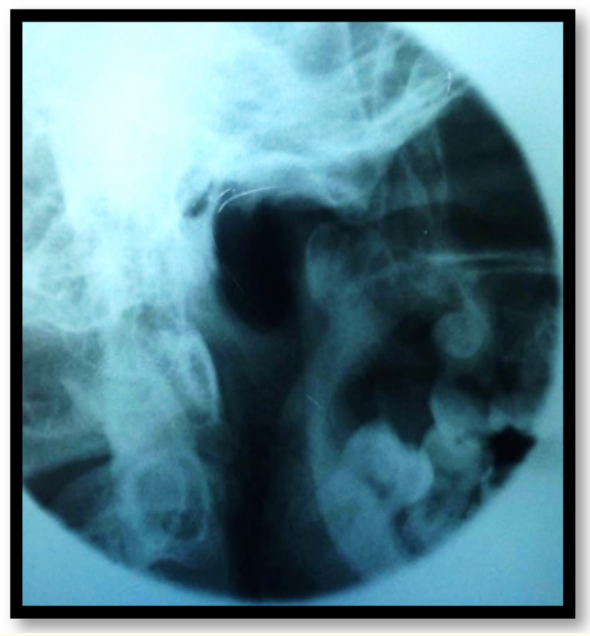

Figure 27

\section{Transorbital view}

- Gives anterior view of TMJ.

- Provides medio-lateral displacement of fractured condylar head [18].

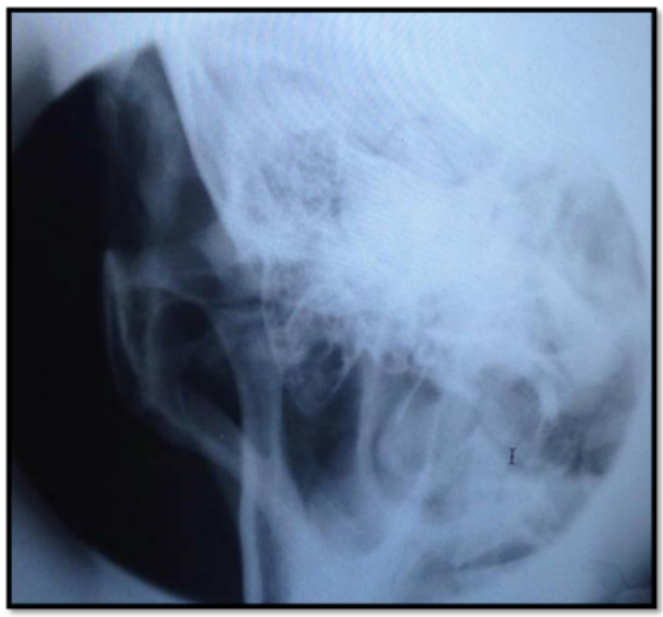

Figure 28
Triple fracture

Magnification sign

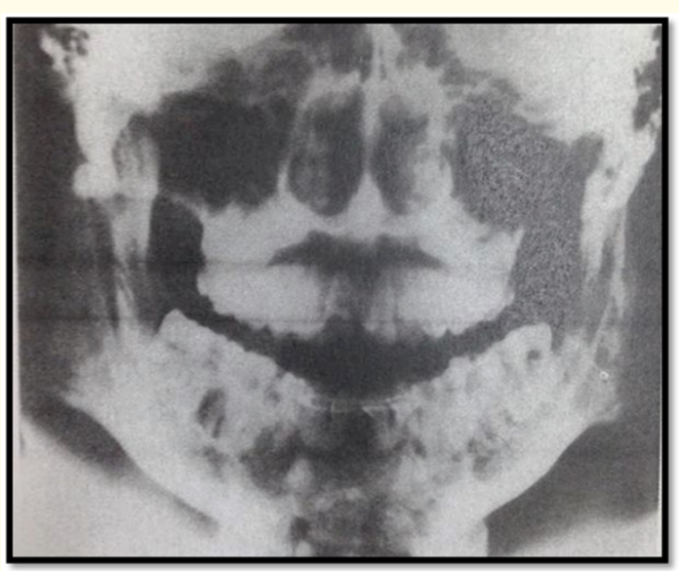

Figure 29

- Bilateral condylar fractures with a symphyseal fracture.

- The lower jaw appears magnified compared with the upper jaw because bilateral lateral displacement of the mandibular bodies [15].

\section{Coronoid fracture}

- Uncommon.

- Occur because of reflex contraction of anterior fibers of temporalis.

- Painful restricted jaw movements esp. protrusion of mandible [22].

- Initial screening radiograph, $\mathrm{OPG}$, doesnot give a clear picture of the coronoid process because of the superimposition of structures [23].

Hence, the ideal radiograph to view the coronoid process is the standard occipitomental view or the 15 degree occipitomental view [11].

Limitations of techniques

- Diminished sensitivity, poor technique, and lack of patient cooperation.

- The symphyseal region on an OPG: overlap from the cervical spine. 


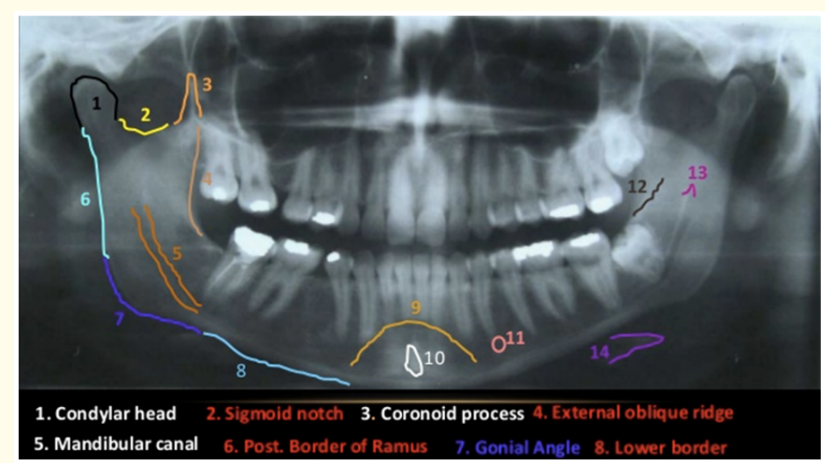

Figure 30

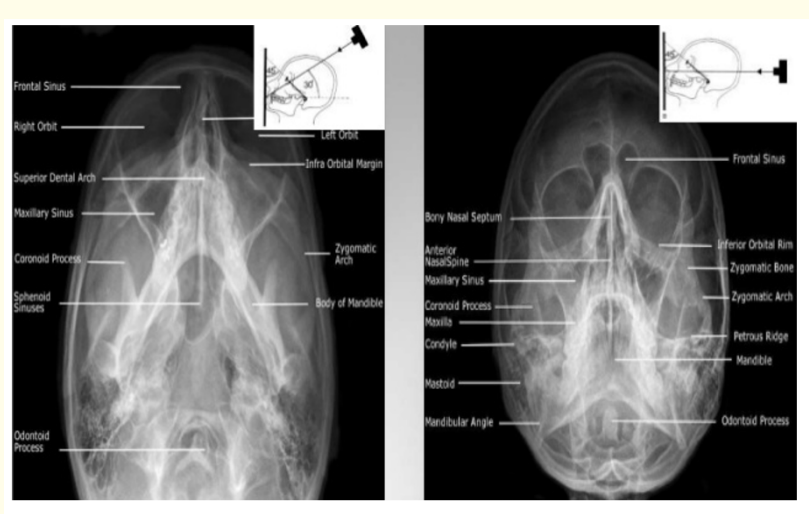

Figure 31

- The PA view: symphysis obscured by the cervical spine, and the condyles can be superimposed over the mastoid process and occipital bone.

- Lateral oblique views: overlap of the contralateral side (body, angle, and/or ramus) of the mandible [24].

Advanced imaging for mandibular fractures

Computed tomography

- Depict all the portions of the mandible in 3 planes.

- It is easier to determine the degree of fragment displacement with CT scanning than with plain radiography.

- Most valuable in the assessment of suspected high-condylar fractures that are difficult to see on plain radiographs.

- For the CT scan examination,
- Direct coronal and axial imaging should be attempted, depending on the patient's mobility.

- If direct coronal scans cannot be obtained, thinner axial sections $(<3 \mathrm{~mm})$ should be included in the protocol to allow for enhanced detail on the sagittal and coronal reconstructed images.

Limitations of imaging mandibular fractures in CT scans

- Mandibular fractures oriented in the same plane as the CT scan section can be obscured.

- Motion artifact on re-constructed CT scan images can mimic a fracture.

- Motion artifact can hide even obvious fractures, which is even more true for reconstructed images [25].

Magnetic resonance imaging

- To evaluate the position and morphology of the articular disc of the TMJ.

- $\quad$ MRI is best for evaluating a torn meniscus or a displaced disk (internal derangement), but rarely is trauma the instigating factor for this study.

- It is also rarely used to evaluate for osteomyelitis that is secondary to mandibular fractures [26].

\section{Conclusion}

For an apt radiographic diagnosis and in fact for an accurate decision as to which radiographic view to advice, we should first be sure after the clinical examination of the mandible, that which region fracture is suspected. And accordingly the appropriate radiographic view should be advised beginning with a screening OPG. And if the OPG fails to reveal any fracture, it does not completely rule out the possibility of fracture. One should further try to investigate for the suspected fracture with the ideal radiographic views but this should always be based on sound clinical examination findings.

\section{Bibliography}

1. E Smith. "Papyrus". In The Edwin Smith Surgical Papyrus, University of Chicago Press, Chicago, Ill, USA, translation by J. H. Breasted (1930).

2. Rowe and Williams. Maxillofacial injuries. Volume 1. Churchill Livingstone D. J. David. 
3. Drake, Vogi And Mitchell. Grey's Anatomy. $3^{\text {rd }}$ Edition. Churchill Livingstone.

4. Lee KH. "Epidemiology of mandibular fractures in a tertiary trauma centre". Emergency Medicine Journal 25.9 (2008): 565568.

5. Anyanechi CE and Saheeb BD. "Mandibular Sites Prone to Fracture: Analysis of 174 Cases in a Nigerian Tertiary Hospital”. Ghana Medical Journal 45.3 (2011): 111-114.

6. Halazonetis JA. "The 'Weak' regions of the mandible". British Journal Surgery 6 (1968): 37.

7. Huelke DF. "Mechanism in the production of mandibular fractures". Journal of Oral Surgery 26 (1968): 86-89.

8. Roode GJ., et al. "Mandibular fractures: an epidemiological survey at the Oral and Dental Hospital, Pretoria". SADJ 62 (2007): 270-274.

9. Serhat Atilgan., et al. "Mandibular fractures: a comparative analysis between young and adult patients in the southeast region of Turkey". Journal of Applied Oral Science 18 (2010).

10. Dr. Philip KM LEE. "Mandibular Condylar Fracture - A Review of Management and Case Reports". The Hongkong Medical Di$\operatorname{ary}(2013)$.

11. JR Moore. Principles of Oral Surgery.

12. Raymond J Fonseca. Oral and maxillofacial trauma. $3^{\text {rd }}$ edition. Elsevier Saunders 1 (2005).

13. David V. Skinner. Cambridge Textbook of Accident and Emergency Medicine.

14. Koshy., et al. "Pearls of mandibular trauma management". Seminars in Plastic Surgery 24 (2010): 357-374.

15. Eric Whaites. "Essentials of Dental Radiography and Radiology". $3^{\text {rd }}$ Edition. Churchill Livingstone.

16. White and Pharoah. Oral Radiology Principles and Interpretation. $6^{\text {th }}$ Edition.

17. Stafne's Oral Radiographic Diagnosis. $5^{\text {th }}$ Edition.

18. Laine FJ., et al. "Radiology of maxillofacial trauma". Current Problems in Diagnostic Radiology 22.4 (1993): 145-188.
19. Gerlock, McBride. Clinical and Radiographic Interpretation of Facial Fractures.

20. Anendd Jadhav., et al. "Mandibular Ramus Fracture: An Overview of Rare Anatomical Subsite". Plastic Surgery International (2015).

21. Alex G Chomenko. Atlas for Maxillofacial Pantomographic Interpretation.

22. Oliveira., et al. "Fracture of the coronoid and pterygoid processes by firearms: case report". Brazilian Dental Journal 18 (2007): 168-170.

23. R Alexander., et al. "Fracture of coronoid process of mandible: an analysis of 52 cases". International Journal of Oral Surgery 14.2 (1985): 126-130

24. Journal of Oral and Maxillofacial Surgery 48 (1990): 1258-1262.

25. Journal of Craniofacial Surgery 16.3 (2005): 394-399.

26. http://emedicine.medscape.com/article/391549overview\#a6

\section{Assets from publication with us}

- Prompt Acknowledgement after receiving the article

- Thorough Double blinded peer review

- Rapid Publication

- Issue of Publication Certificate

- High visibility of your Published work

Website: www.actascientific.com/

Submit Article: www.actascientific.com/submission.php

Email us: editor@actascientific.com

Contact us: +919182824667 